\title{
A DESINTEGRIDADE E A INCOERÊNCIA DA REFORMA TRABALHISTA: A NECESSIDADE DE UMA RESPOSTA ADEQUADA
}

\section{Lenara Giron de Freitas ${ }^{1}$}

Resumo: O trabalho versa sobre o tema do Direito do Trabalho. Nessa perspectiva, seu objetivo consiste em identificar se a reforma trabalhista se revela coerente e íntegra com o Direito Brasileiro, evidenciando de que forma os Juízes devem proceder : devem cumpri-la na integralidade? Para enfrentar tais questionamentos, recorreu-se às contribuições de Ronald Dworkin e de Lenio Streck - doutrinadores que, a partir dos critérios de integridade e de coerência teorizam em busca de uma resposta correta. Os resultados indicaram que a Reforma Trabalhista aprovada não cumpriu o princípio da Integridade na legislação, sendo necessária a atuação do Juiz Hercules.

Palavras-chave: Direito do Trabalho. Reforma Trabalhista. Integridade. Coerência. Constituição. Princípio da Proteção.

\section{THE DISINTEGRITY AND INCOHERENCE OF LABOR REFORM: THE NEED FOR AN ADEQUATE RESPONSE}

\begin{abstract}
This paper deals with the Labor Law. In this perspective, its objective is to identify if the Labor Reform proves to be coherent and just in the Brazilian Law, showing how Judges should proceed: must they comply with entirely? In order to face such questions, we used Ronald Dworkin and Lenio Streck work - which, on the criteria of integrity and coherence, theorize in search of a correct answer, through interpretative analysis. The results indicated that the approved Labor Reform did not comply with the principle of Integrity in the legislation, it will demand action of the judiciary.
\end{abstract}

${ }^{1}$ Doutoranda em Direito pela Universidade do Vale do Rio dos Sinos, na linha de pesquisa Sociedade, Novos Direitos e Transnacionalização. Bolsista de pesquisa no Programa de Excelência Acadêmica da Coordenação de Aperfeiçoamento de Pessoal de Nível Superior (PROEX/CAPES). Possui Mestrado em Direito (2015) pela Universidade do Vale do Rio dos Sinos e Graduação em Ciências Jurídicas e Sociais. Professora em cursos preparatórios para OAB e Concurso. Professora de cursos de Pós-Graduação em Direito e Processo do Trabalho. Integrante do projeto Teoria do Direito e Evolução Social, vinculado ao CNPq-Brasil, coordenado pelo (i) (8)Prof. Dr. Leonel Severo Rocha. Advogada trabalhista.

\footnotetext{
Rev. Revista de Direitos Fundamentais nas Relações do Trabalho, Sociais e Empresariais| e-ISSN: 2525-
} 
Keywords: Labor Law. Labor Reform. Integrity. Coherence. Constitution. Protection Principle.

\section{INTRODUÇÃO}

Às vezes o único meio de promover igualdade exige a limitação da liberdade.

(DWORKIN, 2005, p. 281)

Diante da construção do pós-positivismo despontam vários juristas, dentre os quais, Ronald Dworkin que representa um dos nomes de maior relevância para a teoria da decisão. O grande diferencial de sua obra reside no reconhecimento do Direito como uma atividade interpretativa sem que isso represente a defesa de posturas relativistas. Para tanto, adota os critérios de Coerência e de Integridade, esclarecendo que devem ser cumpridos no plano legislativo e jurisdicional. Principalmente no âmbito da jurisdição, Dworkin visa resolver o problema da discricionariedade sem medida. Para complementar e enriquecer a pesquisa descortinam-se as grandes contribuições do constitucionalista Lenio Streck, para quem as decisões, para serem coerentes e íntegras, devem ser adequadas à Constituição, sem espaços para arbitrariedades.

Reiteradamente, pôde-se constatar nos julgados a falta de critérios à luz da integridade do Direito - inclusive ocorrendo em muitos julgados a filiação incorreta a determinados métodos de interpretação do fenômeno jurídico. Ao estudar alguns julgados (também do Supremo Tribunal Federal (STF) na disciplina do Doutorado ministrada por Lenio Streck), comprovou-se que inexiste qualquer tipo de constrangimento, de cunho teórico e institucional, que oriente a atividade do intérprete na aplicação do direito, eis que imerso na solidão de suas próprias crenças e de seus pensamentos, a ponto de subverter teorias, em razão do sentido que pretenda atribuir às suas decisões em um contexto de solipsismo judicial.

Com isso, a imprevisibilidade, a incerteza e a insegurança jurídica contaminam o Direito nacional. As decisões variam de acordo com as experiências, os ideais morais, o sentimento de justiça e as convicções políticas e econômicas individuais de cada magistrado o que contempla uma preocupação do mundo jurídico trabalhista, haja vista que direitos trabalhistas historicamente conquistados passaram por uma grande reforma, com sérias Rev. Revista de Direitos Fundamentais nas Relações do Trabalho, Sociais e Empresariais| e-ISSN: 2525- 
lacunas que dependerão de entendimentos judiciais - o que sinaliza a extrema importância da análise interpretativa íntegra e coerente em relação aos valores e aos princípios constitucionais que compõem o Direito do Trabalho.

Destarte, o estudo consistiu em identificar se a Reforma Trabalhista se mostra coerente e íntegra no conjunto do Direito brasileiro e em desvendar de que forma os Juízes devem proceder diante da entrada em vigor da Lei 13.467/17. Nessa perspectiva, devem então cumpri-la na integralidade? Poderia o Juiz não cumprir a literalidade da lei? Portanto, o estudo em questão pretendeu analisar a Reforma Trabalhista a partir dos ensinamentos de Ronald Dworkin e das contribuições do professor Lenio Streck, com o objetivo de aprimorar a teoria da decisão no âmbito trabalhista. Com o intuito de alcançar o objetivo proposto pelo artigo, o texto se estruturou em três capítulos.

A escolha da temática se deve à repercussão nacional e à importância de os julgamentos demandarem critérios interpretativos, sob a pena de traduzir arbitrariedades dos juristas, num fenômeno que pode se mostrar bastante nocivo ao Direito do Trabalho.

\section{A FIGURA DO JUIZ HÉRCULES}

Ronald Dworkin é um dos maiores filósofos do Direito dos séculos XX e XXI com suas elucubrações para o pensamento jurídico contemporâneo. A realidade é que, já em seus primeiros escritos, Dworkin busca uma saída alternativa, recorrendo à filosofia mais crítica da época (a hermenêutica) e inserindo o jurídico na hermenêutica-crítica. (CHUEIRI, 2013, p. 182). A articulação entre hermenêutica e crítica constitui condição epistemológica para um Direito que nega, ao mesmo tempo, a fundamentação positivista (CHUEIRI, 2013, p. 183)² e jusnaturalista, sem contudo se deslocar do horizonte da modernidade. (CHUEIRI, 2013, p. 182).

Considerando-se o cenário examinado, tem-se Dworkin na discussão jurídica entre positivismo exegético - que identifica lei e direito - e os diversos pós-exegéticos - que surgem

\footnotetext{
${ }^{2}$ Dworkin pretende mostrar como os indivíduos podem ter outros direitos jurídicos que não aqueles explícitos pela legislação (decisão política) ou pela prática social (pelo costume) ou ainda pela decisão judicial (pelo precedente).
}

Rev. Revista de Direitos Fundamentais nas Relações do Trabalho, Sociais e Empresariais| e-ISSN: 2525-

9903| Evento Virtual| v. 6 | n. 1 | p. 80-102 | Jan/Jun. 2020 
para salvar o jurista de realizar mera atividade mecânica, incluindo o elemento discricionariedade, como não adepto a nenhum dos dois. (STRECK, 2016, p. 331). E como se a Crítica Hermenêutica do Direito complementasse, a hermenêutica (de cariz filosófico) possibilita a construção das condições para a criação desse terceiro caminho a ser trilhado. (STRECK, 2016, p. 331). De mais a mais, ao vislumbrar as obras de Dworkin, nota-se que desenvolvem preliminarmente condições de produção de um discurso crítico, na medida em que sua fala se revela interdisciplinar: Direito, moral, política e arte estão comprometidos na significação de um tempo, de uma forma de vida que é a modernidade. (ROCHA, 2013, p. 33-34). Logo, a proposta filosófica de Dworkin pode ser referida como a tradução do tempo na modernidade.

O objetivo do estudioso foi examinar a solidez do positivismo jurídico ${ }^{3}$, especialmente na forma mais elegante e sofisticada de Hebert Hart, apontando assim as principais críticas ao: a) modelo de regras, as quais são identificadas apenas a partir de critérios específicos de testes que não têm a ver com conteúdo, mas com pedigree ${ }^{4}$, excluindose outros valores de importância para o Direito; b) crítica à discricionariedade da autoridade pública, quando esta utiliza seu discernimento pessoal, sem qualquer critério quando o caso não pode ser decidido mediante a aplicação do direito; c) crítica à obrigação jurídica apenas quando houver uma norma jurídica válida, inexistindo obrigação jurídica quanto não houvesse a tal regra jurídica válida. (DWORKIN, 2007, p. 28).

A realidade é que as críticas elencadas por Dworkin ao positivismo de Hart desencadeou um debate entre ambos e agregou mais subsídios à teoria da Decisão Jurídica.

\footnotetext{
${ }^{3} \mathrm{O}$ positivismo nunca se preocupou em responder o problema central do direito por considerar a discricionariedade judicial como uma fatalidade. Nesse contexto, muitos que se intitulam pós-positivistas, em realidade, só estão agindo contra o positivismo exegético (de há muito superado), acabando por aceitar o positivismo normativista, na medida em que defendem a existência de um grau de discricionariedade nas decisões judiciais.

${ }^{4}$ No positivismo, "Estes testes de pedigree podem ser usados para distinguir regras jurídicas válidas de regras jurídicas espúrias (regras que advogados e litigantes erroneamente argumentam ser regras de direito) e também de outros tipos de regras sociais (em geral agrupadas como "regras morais") que a comunidade segue mas não faz cumprir através do poder público. (DWORKIN, 2007. p. 28)
}

Rev. Revista de Direitos Fundamentais nas Relações do Trabalho, Sociais e Empresariais| e-ISSN: 2525-

9903 | Evento Virtual| v. 6 | n. 1 | p. 80-102 | Jan/Jun. 2020 


\subsection{Integridade e Coerência na Atividade Legislativa e Judicial}

Dworkin (1999, p. 274) divide a exigência de integridade em dois princípios: Princípio da Integridade na Legislação (no sentido de a legislação criada precisar estar coerente com alguns princípios) e Princípio da Integridade no Julgamento (em que os responsáveis por decidir devem conceber o corpo do Direito em todo seu conjunto). Logo, um princípio legislativo demanda aos legisladores que tentem tornar o conjunto de leis moralmente coerente e um princípio jurisdicional requer que o juiz opte pela interpretação que, do ponto de vista da moral política, melhor reflita a estrutura das instituições e as decisões da comunidade - ou seja, a que melhor represente o direito histórico vigente constitucionalmente adequado (STRECK, 2012, p. 230), o que seria, assim, a resposta correta para o caso concreto 5 .

No caso específico da decisão judicial, a coerência e a integridade se manifestam como elementos de igualdade, de forma que diversos casos devem ser julgados com igual consideração. Segundo Streck (2017b, p. 34), para elucidar, conceitualmente, a "coerência liga-se à consistência lógica que o julgamento de casos deve guardar entre si”" (sem que seja entendido isso como simples fato de que cada nova decisão deve seguir o que foi decidido anteriormente). Dando continuidade à conceituação, "a integridade contempla a exigência de que os juízes construam argumentos de forma integrada ao conjunto do Direito." (STRECK, 2017 , p. 34) ${ }^{6}$. Nisso a integridade freia atitudes solipsistas- voluntaristas dos julgadores, em que o legislador não pode dar um drible hermenêutico, decidindo conforme a sua consciência (STRECK, 2012, p. 32-34) 7 .

\footnotetext{
${ }^{5}$ Streck (2017, p. 277) a partir da Crítica Hermenêutica do Direito, denomina a resposta correta como aquela adequada à Constituição.

6 Lenio Streck, a partir da Crítica Hermenêutica do Direito, denomina a resposta correta, como aquela adequada à Constituição.

7 Nesse sentido, a crítica de Streck se desenvolve contra o positivismo normativista de Kelsen, ou seja, contra aquele que admite discricionariedades (ou decisionismos e protagonismos judiciais. Para Kelsen, a interpretação do Direito seria eivada de subjetivismos provenientes de uma razão prática solipsista. Assim, apostou na discricionariedade do intérprete (no nível de aplicação do Direito) como uma fatalidade, exatamente para salvar a pureza metódica, que assim permanecia a salvo da subjetividade. Com isso, superou o positivismo exegético, mas, no entanto, deixou de lado o principal problema do Direito: a interpretação concreta, no nível da aplicação, assim como modernas teorias que se intitulam neoconstitucionais estão fazendo.
}

Rev. Revista de Direitos Fundamentais nas Relações do Trabalho, Sociais e Empresariais| e-ISSN: 2525-

9903 | Evento Virtual| v. 6 | n. 1 | p. 80-102 | Jan/Jun. 2020 
$\mathrm{Na}$ análise de casos difíceis ou no momento em que o julgador necessita mudar uma decisão, o entendimento deve ser enfrentado por todos os elementos que compõem o caso. Dworkin, em seus escritos, exibe exemplos de como fazê-lo, demonstrando que pelos questionamentos é possível ter acesso "a situação com a melhor luz, do modo mais adequado sob a perspectiva da coerência e integridade do direito."» (STRECK, 2016, p. 336) Para tanto, Dworkin apresenta o Juiz Hércules.

\subsubsection{A Figura do Juiz Hércules}

Dworkin propõe um jurista dotado de capacidades extraordinárias e sobre-humanas, chamado Hércules (que deve ser entendido como uma metáfora) destinado a apurar em cada caso difícil os princípios que viabilizem as regras vigentes e que garantam a melhor justificação moral para uma solução. À luz do método de Hércules, confia-se nos Juízes, no sentido de que podem proferir sentenças corretas nos casos difíceis e manter-se sempre no domínio da aplicação do Direito, sem passar ao campo da criação de normas jurídicas (RODRIGUEZ, 1997, p. 38). Por conseguinte, o trabalho de Hércules exige do intérprete capacidade sobrelevada para sair de uma condição de interpretação dita normal, com vistas a aproximar-se daquilo que se pode classificar como justo como resultado da integridade do Direito (DWORKIN, 1999, p. 379-380), considerando o texto jurídico, os antecedentes históricos até o momento decisório, os valores, os princípios e (especialmente) a previsão constitucional.

Nessa lógica, deverá ser analisado pelos magistrados Hércules como decidir os casos difíceis em que a literalidade da Lei 13.467 contradiz, em seu cerne, o pilar da construção do Direito do Trabalho, em que se traduz o Princípio da Proteção ${ }^{9}$ - o qual engloba a base do

8 Lenio Streck, parafraseando Dworkin, traz um exemplo de um caso em que em decisões anteriores se decidia que entre todas as demais profissões, os advogados eram os únicos imunes aos danos causados por negligência. Todavia chega agora um novo caso envolvendo o caso. Não necessariamente o julgador tem que decidir conforme decisões anteriores, o fundamento de falta de igualdade a coerência pode ser quebrada pela integridade, mas para isso existe um conjunto de questionamentos que devem ser feitos para que se chegue à resposta final, a mais correta possível. No mínimo, deve-se perguntar: já existe algum entendimento sobre o tema? Essa nova causa se diferencia das que já existem por algum elemento? Houve alguma alteração normativa durante o lapso temporal que envolve as duas causas? Por que os demais profissionais são responsabilizados? Por que, à época, os advogados eram imunes? É possível manter atualmente o mesmo argumento jurídico? Tudo isso para promover a melhor decisão.

9 Segundo Pires (2011), para entender a necessidade, é preciso adentrar na construção histórica da gênese do Direito do Trabalho, que reside na chamada revolução industrial, a qual trouxe em seu seio a questão social de exigir medidas legais específicas com vistas à reordenação do fenômeno da mão de obra. Após muita luta,

Rev. Revista de Direitos Fundamentais nas Relações do Trabalho, Sociais e Empresariais| e-ISSN: 2525-

9903 | Evento Virtual| v. 6 | n. 1 | p. 80-102 | Jan/Jun. 2020 


\section{A DESINTEGRIDADE E A INCOERÊNCIA DA REFORMA TRABALHISTA:}

A NECESSIDADE DE UMA RESPOSTA ADEQUADA

ordenamento trabalhista, cuja única finalidade é igualar os desiguais, ou melhor, amparar o trabalhador na relação de emprego de forma a mantê-lo no mesmo nível do empregador, a fim de concretizar a igualdade material.

Caberá ao magistrado Hércules interpretar a Reforma Trabalhista e dar-lhe sentido em cada caso. Assim, quando Streck (2010, p. 83) afirma que interpretar é aplicar, está dizendo que os sentidos só irão aparecer no ato aplicativo. Além disso, a questão do sentido vai se situar antes do problema do conhecimento, isso porque a compreensão é antecipada (por isso, obviamente, pré-compreensão), não sendo algo que pode ser dominado. O sentido não estará disponível para o intérprete, e por essa razão, assevera que não interpretamos para compreender, e, sim, compreendemos para interpretar. E finalmente, se hermenêutica é sinônimo de compreensão, é necessário compreender infraconstitucionalidades, e a partir de critérios de coerência e de integridade, buscando a resposta constitucionalmente correta, no sentido de que cada norma infraconstitucional há de ser aplicada juntamente com os princípios constitucionais.

Destarte, não se pode desconsiderar que a ideia nuclear da coerência e de integridade compreende o princípio da igualdade, o qual decorre da concretização de uma análise mais ampla de outros princípios constitucionais que completam a Integridade do Direito, como o princípio da Igualdade, da Liberdade e da Dignidade da Pessoa Humana. (DWORKIN, 2007, p. 304-305 $)^{10}$. Convém examinar de que forma a teoria de Dworkin com os critérios de Integridade e de Coerência pode contribuir para a análise da Reforma Trabalhista e auxiliar os Juízes a captar a resposta certa diante de tanta contradição na lei ordinária.

verificou-se a necessidade de normatizar as relações de trabalho de modo que os empregados não se obrigassem de forma dependente e humilhatória aos empregadores em busca do labor. Era necessário que o Estado intervisse nas relações de trabalho-emprego, para proporcionar maior dignidade ao trabalhador que, até então, estava totalmente exposto ao poder discricionário do empregador.

${ }^{10} \mathrm{Na}$ percepção de Dworkin, para levar os direitos a sério e aceitar que o governo os respeite, deve-se aderir, no mínimo, à ideia vaga, mas poderosa, da dignidade humana, a qual, associada à ideia de Kant e defendida por filósofos de diferentes escolas, pressupõe que existem maneiras de tratar um homem que são incompatíveis com seu reconhecimento como um membro pleno da comunidade humana e, se ocorrer, deve ser considerado profundamente injusto em qualquer localidade do mundo.

Rev. Revista de Direitos Fundamentais nas Relações do Trabalho, Sociais e Empresariais| e-ISSN: 2525-

9903| Evento Virtual| v. 6 | n. 1 | p. 80-102 | Jan/Jun. 2020 


\section{DIREITO DO TRABALHO PÓS-REFORMA TRABALHISTA A PARTIR DAS CONTRIBUIÇÕES DE RONALD DWORKIN}

Em meio à grave crise econômica, social e política foi aprovada a maior Reforma Trabalhista do país, com mais de cem alterações nos artigos da CLT ${ }^{11}$. Poucos meses após o julgamento de um alarmado impeachment (STRECK, 2015 a) ${ }^{12}$, o projeto foi apresentado em vinte e oito de abril de 2017, e em sete meses consagrou-se lei, após sofrer algumas intervenções na Câmara dos Deputados, sem contudo ser modificado (PLC 38/2017). Além disso, o projeto político não foi debatido e discutido com a sociedade - a qual, bem pelo contrário, sequer foi ouvida.

Por ser um ato extremamente bizarro, vale comentar que durante a tramitação do Projeto de Lei da Reforma Trabalhista, foi aberta Consulta Pública (PLC 38/2017), na qual 172.154 pessoas votaram contra a Reforma Trabalhista, e 16.789 pessoas a favor. Os números escancaravam o desejo da sociedade, o que foi totalmente desconsiderado: nem mesmo com fins políticos a voz popular foi observada, em total descompasso com a democracia. Diante disso, a única alternativa que resta ao Brasil é poder contar com um Poder Judiciário que não ignore a ideia nuclear da coerência e da integridade, em uma análise mais ampla dos princípios constitucionais que fazem parte da Integridade do Direito do Trabalho, como os Princípios da Igualdade, da Liberdade e da Dignidade da Pessoa Humana.

\subsection{A Incoerência na Reforma Trabalhista e a Necessidade do Magistrado Hércules}

Dworkin (1999, p. 274) - como já se abordou - divide a exigência de integridade em dois princípios: o primeiro, o da Integridade na Legislação, sustenta que os legisladores são

\footnotetext{
11 Nesse sentido: São tempos difíceis, tempos duros os que vivemos. Crise econômica, crise social. Crise política, crise jurídica. O Brasil e sua perene circunstância de modernidade tardia. Por aqui, institucionalizar a civilização é uma moeda de dois lados: a barbárie vem com ela também institucionalizada. Talvez esse não seja um traço exclusivo do Brasil, mas uma herança patrimonialista para alguns (Raymundo Faoro), escravocrata para outros (Jessé de Souza). STRECK, Lenio Luiz. Como usar a jurisdição constitucional na reforma trabalhista. Consultor Jurídico, São Paulo, 2 nov. 2017. Disponível em: <https://www.conjur. com.br/2017-nov-02/senso-incomum-usar-jurisdicao-constitucional-reforma-trabalhista>. Acesso em: 06 ago. 2018.

12 No mesmo sentido, ver o artigo: STRECK, Lenio Luiz. Não há elementos jurídicos para impeachment de Dilma, rebatem juristas. Consultor Jurídico, São Paulo, 4 fev. 2015b. Disponível em: <https://www.conjur.com.br/2015-fev-04/nao-elemento-juridico-impeachment-dilma-dizem-advogados>. Acesso em: 06 ago. 2018.
}

Rev. Revista de Direitos Fundamentais nas Relações do Trabalho, Sociais e Empresariais| e-ISSN: 2525- 
responsáveis por tornar o conjunto de leis moralmente coerente, e a legislação deve coadunar com os princípios, os fatos históricos e as necessidades da sociedade. E neste momento já se pode adiantar que a Reforma Trabalhista não ocorreu de forma responsável. Num contexto geral, a Reforma Trabalhista foi aprovada com diversas possíveis interpretações de inconstitucionalidades, em total desordem. Portanto, cabe mensurar alguns dispositivos a partir das contribuições da Teoria de Ronald Dworkin, no tocante ao Princípio da Integridade da Legislação.

\subsection{Direito Moral de que Juízes sejam Hércules}

Embora as pessoas tenham um forte direito moral de que os Tribunais imponham os direitos aprovados (DWORKIN, 2005, p. 14) ${ }^{13}$, deve restar claro que essa afirmação pode ter ressalvas em uma democracia cujas leis são fundamentalmente injustas, quando realmente precisa-se ir além do texto jurídico como fonte exclusiva de tais direitos. Na lógica deste trabalho, cabe refletir que se demonstrou que o texto da Reforma Trabalhista pode ser considerado como uma lei fundamentalmente injusta e, por isso, precisa de uma interpretação íntegra e coerente para sua aplicação.

Os textos legais injustos surgidos com a Reforma Trabalhista englobam aqueles que votados às pressas, sem grandes estudos e discussões com a sociedade, trouxeram diversas inconstitucionalidades e antinomias. E, por isso, seu texto legislativo não pode servir única e exclusivamente na decisão de casos, bem como em algumas hipóteses, nem mesmo deve ser aplicado. Lenio Streck (2013) enumera seis hipóteses em que a lei, no caso, trabalhista votada pelo Parlamento, pode deixar de ser aplicada:

Há muito tenho insistido na tese de que uma lei votada pelo Parlamento só pode deixar de ser aplicada em seis hipóteses: a) se for inconstitucional, b) se for possível uma interpretação conforme a Constituição, c) se for o caso de nulidade parcial sem redução de texto, d) no caso de uma inconstitucionalidade parcial com redução de texto, e) se se estiver em face de resolução de antinomias e f) no caso do confronto entre regra e princípio (com as ressalvas hermenêuticas no que tange ao pamprincipiologismo). Fora disso, estar-se-á em face de ativismos, decisionismos ou

${ }^{13}$ É por isso que alguns casos são casos fáceis no modelo centrado nos direitos, assim como no modelo centrado no texto jurídico.

Rev. Revista de Direitos Fundamentais nas Relações do Trabalho, Sociais e Empresariais| e-ISSN: 2525-

9903| Evento Virtual| v. 6 | n. 1 | p. 80-102 | Jan/Jun. 2020 
coisa do gênero. Portanto, o judiciário possui amplo espaço. Nada mais, nada menos do que seis maneiras. Mas parece que, na cotidianidade, o judiciário prefere um atalho. Sim, um atalho solipsístico. (STRECK, 2013

Isso também significa que as decisões dos Juízes do Trabalho não se tratam de uma escolha livre a respeito de aplicar (ou não) as alterações da CLT, mas sim de uma interpretação, enfrentando os argumentos que compõem o caso, com argumentos de coerência e de integridade, com responsabilidade política, sem construir leis, pois "juiz não constrói leis; segue padrões interpretativos." (STRECK, 2015c, p. xx). Antes mesmo da Reforma Trabalhista, no ano de 2015, ocorreu uma grande alteração no Código de Processo Civil (CPC), por meio de incentivos da Crítica Hermenêutica do Direito, com contribuições de Lenio Streck (2015, p. 297) ${ }^{14}$, retirando-se o livre convencimento (artigo 371) do antigo CPC e introduzindo-se textualmente a exigência de coerência e de integridade no atual artigo 926 do CPC, o qual estabelece que "os tribunais devem uniformizar sua jurisprudência e mantê-la estável, íntegra e coerente", aplicado subsidiariamente ao processo do trabalho, conforme artigo 769 da CLT. No ponto de vista de Streck:

Simplesmente o legislador quis dizer o seguinte: o cidadão quando vai ao judiciário não vai pedir a opinião pessoal do juiz sobre determinado assunto; ele quer que o juiz diga o que o direito tem a dizer para ele. O legislador despersonalizou a aplicação da lei; em outras palavras: em uma democracia, nãose pode depender da bondade ou da maldade de quem vai dizer o direito. (STRECK, 2015, p. 113)

Por outro lado, a Reforma deixou passar a possibilidade de alteração do artigo 765 da CLT, segundo o qual "Os Juízos e Tribunais do Trabalho terão ampla liberdade na direção do processo e velarão pelo andamento rápido das causas, podendo determinar qualquer diligência necessária ao esclarecimento delas", o que pode ser compreendido de forma errônea, justificando atuações discricionárias sem medida.

Entretanto, voltando-se ao cerne da questão de que ao Juiz não é dada ampla liberdade, há de ficar registrado que em sua atuação há obrigatoriedade de observância dos comandos da Constituição. Nesse contexto, o que deve se ter em mente é que o Direto do Trabalho contempla um direito fundamental, constitucionalmente assegurado, cujo respeito

${ }^{14}$ Nas palavras de Streck: "Por emenda supressiva do relator Paulo Teixeira, atendendo à minha sugestão e contando com a aquiescência de Fredie Didier, Dierle Nunes e Luis Henrique Volpe, todas as referências de que-ojuiz-teria-o-poder-de-livre-convencimento foram colocadas em um exílio epistêmico. Isto é: foram retiradas do ordenamento processual. Neste ponto, viva o NCPC!”.

Rev. Revista de Direitos Fundamentais nas Relações do Trabalho, Sociais e Empresariais| e-ISSN: 2525-

9903| Evento Virtual| v. 6 | n. 1 | p. 80-102 | Jan/Jun. 2020 
aos direitos individuais e coletivos do trabalhador consagrados na própria Constituição inclusive de forma explícita, ao não levantar dúvidas acerca de sua aplicabilidade e funcionabilidade. (FERRAZETE FILHO; MATZENBACHER, 2016, p. 76).

Destarte, a Constituição eleva uma série de direitos dos trabalhadores ao mesmo status dos direitos fundamentais clássicos, dos quais resulta certo que quem trabalha, ainda que de modo subordinado ou por conta alheia, continua cidadão e portador de dignidade circunstância que permite compreender o porquê da precedência a ser conferida à proteção dos direitos de personalidade dos trabalhadores, quando confrontados com o poder diretivo do empregador. (LEDUR, 2010, p. 13).

Nessa seara, é certo que a Constituição possui como viés os direitos básicos e fundamentais direcionados à proteção do trabalhador das mais diferentes formas, a fim da busca incessante pela igualdade e pela justiça. Aqui cabe lembrar que os Princípios de Liberdade e de Igualdade com frequência entram em conflito, pois às vezes o único meio eficaz de promover a igualdade exige certa limitação de liberdade, e as consequências de promover a liberdade são prejudiciais à igualdade.

Os princípios jurídicos-constitucionais se caracterizam por instituir o mundo prático no Direito, e por esse ângulo o Juiz tem o dever de decidir de forma adequada, ou seja, conforme a Constituição, e assim, a normatividade assumida pelos princípios possibilita "um fechamento interpretativo" próprio da blindagem hermenêutica contra discricionarismos judiciais. Nesse âmbito, as cláusulas constitucionais deveriam ser compreendidas como restrições e limitações ao Poder Público, sempre favorecendo a preservação dos direitos dos cidadãos. (STRECK, 2016).

O STF, como guardião das promessas constitucionais, tem a grave responsabilidade de assegurar o respeito aos valores humanistas e sociais que envolvem o trabalho humano. Atualmente, há pelo menos vinte ADIs em face da lei da Reforma Trabalhista focadas no trabalho intermitente, na tarifação do dano moral, na insalubridade nas atividades de gestantes, nos honorários sucumbenciais que aguardam o julgamento da Suprema Corte. Há de constar que dentre elas a grande maioria se refere à Contribuição Sindical, a qual foi a primeira ADI improcedente, ou seja, que não conheceu a inconstitucioanalidade do dispositivo. Isso quer dizer que o restabelecimento da integridade e da coerência da CLT e da 
dignidade de milhões de trabalhadores depende do julgamento dessas ações. Logo deve o STF, órgão da cúpula do Poder Judiciário, exercer a função que lhe foi conferida de guarda da Constituição, conforme sublinha seu artigo 102. (PAES, 2018).

Também há de constar que os cidadãos têm o direito moral de que o Juiz de primeiro grau seja o Hércules - ou melhor, que tencione encontrar em cada caso difícil os princípios que elucidem as regras vigentes com vistas a aproximar-se o mais perto possível daquilo que se pode classificar como justo, como resultado da integridade do Direito (DWORKIN, 1999, p. 379-380), considerando o texto jurídico, os antecedentes históricos até o momento decisório, os valores, os princípios e a previsão constitucional, e assim viabilizem a melhor justificação moral para a solução do caso, mantendo o domínio da aplicação do Direito, sem passar ao campo da criação de normas jurídicas. (RODRIGUEZ, 1997, p. 38).

Ao Juiz não se concede ampla liberdade, por isso em sua atuação pode até considerar a aplicação da lei, mas não de forma isolada, posto que a lei trabalhista que se insere à luz da proteção constitucional e à luz da legislação internacional. Entretanto, ocorre que na primazia da realidade (termo utilizado no processo do trabalho para se ter acesso à verdade real) até o momento, passados quase dez meses da publicação da Lei 13.467, apenas uma ADI foi julgada no STF. Também, os Juízes de Primeiro Grau (diante da quantidade de processos que tramita em cada Vara do Trabalho) têm dificuldades em julgar ações que passaram a ser consideradas casos difíceis no âmbito da justiça do trabalho. Seja pela falta de tempo, visto que a quantidade de processos em cada Vara do Trabalho é significativa, seja em razão da dificuldade de cumprir a Teoria da Decisão, que exige um ato interpretativo além do modelo de regras.

Considerando-se os fatores mencionados e a preocupação com o conteúdo das regras apresentado pela Reforma Trabalhista, os atores do mundo do trabalho, antes mesmo da vigência da lei, passaram a realizar jornada, publicar teses e enunciados, com o objetivo de auxiliar os operadores do Direito. Portanto, convém examinar de que forma Enunciados e Teses são vistos na perspectiva Dworkina e pela teoria hermenêutica da decisão de Streck. 


\section{A DESINTEGRIDADE E A INCOERÊNCIA DA REFORMA TRABALHISTA:}

A NECESSIDADE DE UMA RESPOSTA ADEQUADA

\subsection{Jornadas Trabalhistas e Análise da Integridade e da Coerência dos Enunciados}

Após a aprovação da Reforma Trabalhista, diversos atores do mundo do trabalho passaram a se manifestar, a fim de auxiliar na sua interpretação, publicando então um workshop de enunciados ${ }^{15}$. Há de constar que Lenio Streck já publicou diversos escritos com sua crítica aos enunciados, postulando que tentam transportar a realidade para dentro de conceitos. "Lei e direito sendo a mesma coisa. Não há espaço para a faticidade. É como se fosse possível fazer juízos abstratos."(STRECK, 2015f). "Nítido drible da vaca hermenêutico. Laboram com conceitos sem os casos. Os conceitos antes dos casos". Ademais, o Enunciado envolve um desrespeito à autonomia do Direito. Consequentemente, trata-se de um desrespeito à democracia e conspurca até mesmo a forma como os Poderes organizados na CF: Legislativo, Executivo e Judiciário, nessa ordem, mesmo que o Parlamento esteja com problemas (STRECK, 2015f). Ao debater a respeito do tema, após ser instigado pelo professor Lenio Streck, Dworkin respondeu pessoalmente à questão:

[..] 'e os enunciados, Professor Dworkin?'. A resposta veio, novamente acompanhada de um sorriso: 'Caro Lenio, é muito simples. Os legisladores do Código de Processo Civil foram muito bem quando levaram em conta essa nossa chatice - minha e sua - de exigir coerência e integridade. E esses tais enunciados passam longe desses deveres. Interpretar o Direito sob sua melhor luz passa por respeitar a supremacia do Poder Legislativo. Se Herbert diz que o Direito é um conjunto de regras, eu, por outro lado, disse por muito tempo que é um conjunto de regras e princípios. Bem, acho que todos (você, Herbert, eu, Kelsen et caterva) concordamos que o Direito definitivamente não é um conjunto de enunciados. Sem contar que mais tarde eu até abandonei esse 'conjunto de regras e princípios' e passei a considerar um sistema único, segundo o qual todo o Direito é validado por razões substantivas. Veja: razões substantivas, não enunciados'. Disponível em $\mathrm{O}$ problema é que eu, anfitrião do encontro, continuava incomodado com os enunciados, principalmente depois que descobri que já estão fazendo seminários para... explicar os enunciados. Insisti: 'e os enunciados, Professor Dworkin?'. A resposta veio, novamente acompanhada de um sorriso: 'Caro Lenio, é muito simples. Os legisladores do Código de Processo Civil foram muito bem quando levaram em conta essa nossa chatice - minha e sua — de exigir coerência e integridade. E esses tais enunciados passam longe desses deveres. Interpretar o Direito sob sua melhor luz passa por respeitar a supremacia do Poder Legislativo. Se Herbert diz que o Direito é um conjunto de regras, eu, por outro lado, disse por muito tempo que é um conjunto de regras e princípios. Bem, acho que todos (vocês, Herbert, eu, Kelsen et caterva) concordamos que o Direito definitivamente não é um conjunto de enunciados. Sem contar que mais tarde eu até abandonei esse 'conjunto de regras e princípios' e passei a considerar um sistema único, segundo o qual todo o

15 Termo utilizado por Lenio Streck. O autor critica os Workshops de enunciados jurídicos. Rev. Revista de Direitos Fundamentais nas Relações do Trabalho, Sociais e Empresariais| e-ISSN: 2525-

9903| Evento Virtual| v. 6 | n. 1 | p. 80-102 | Jan/Jun. 2020 
Direito é validado por razões substantivas. Veja: razões substantivas, não enunciados'. ${ }^{16}$ (STRECK, 2017a, p. xx)

Isso não significa que tudo que estiver positivado na Lei 13.467 deve ser cumprido, o que "seria retroceder justamente ao exegetismo." (STRECK, 2015f, p. xx) . A fim de justificar tal afirmação, Streck (2013) traz na sua teoria hermenêutica da decisão (CHD) seis ${ }^{17}$ hipóteses nas quais o Judiciário pode deixar de aplicar a lei ou um dispositivo legal (texto jurídico na linguagem hermenêutica). (STRECK, 2015f). Diante das críticas, nota-se que a montanha de enunciados surgidos após a publicação da Lei 13.467 pode ser considerada mais um produto negativo da Reforma Trabalhista, porém em uma visão mais ampla, quando os Enunciados estiverem devidamente fundamentados às seis hipóteses, talvez possa cumprir um papel de doutrina, a fim de proteger o ordenamento jurídico constitucional trabalhista.

A realidade é que, dentre essas jornadas de enunciados, há vozes firmes contra as incoerências da Reforma Trabalhista, tais como o Ministério Público do Trabalho (MPT), a Ordem dos Advogados do Brasil (OAB), a Associação Nacional dos Magistrados da Justiça do Trabalho (ANAMATRA), a Associação dos Juízes Federais do Brasil (AJUFE), a Associação dos Magistrados Brasileiros (AMB), a Associação Nacional dos Membros do Ministério Público (CONAMP), a Associação Nacional dos Procuradores do Trabalho (ANPT), a Associação Nacional do Ministério Público Militar (ANMPM), a Associação Nacional dos Procuradores da República (ANPR), a Associação do Ministério Público do Distrito Federal e Territórios (AMPDFT), a Associação Brasileira dos Advogados Trabalhistas (ABRAT), a Associação dos Magistrados do Distrito Federal (AMAGIS/DF), o Sindicato Nacional dos Auditores-Fiscais do Trabalho (SINAIT) e a Confederação Nacional dos Bispos Brasileiros (CNBB) (HONÓRIO; OLIVEIRA, 2017). Entre esses órgãos, muitos já se posicionaram, como explicita a Nota Técnica $n^{\circ} 5$ do MPT:

No mesmo sentido, há diversas proposições que dificultam e encarecem a tutela jurisdicional ao trabalhador, dificultando-lhe o acesso à Justiça. Como exemplo, apontamos a possibilidade do trabalhador ser responsabilizado pelo pagamento de

16 STRECK, Lenio Luis. Na Dacha, teóricos do mundo dizem: a verdade não está no enunciado! Consultor Jurídico, São Paulo, 19 de outubro de 2017. Disponível em: <https://www.conjur.com.br/2017-out-19/sensoincomum-dacha-teoricos-mundo-dizem-verdade-nao-enunciado>. Acesso em: 07 ago. 2018.

17 1) se for inconstitucional, 2) se for possível uma interpretação conforme a Constituição, 3) se for o caso de nulidade parcial sem redução de texto, 4) no caso de uma inconstitucionalidade parcial com redução de texto, 5) se se estiver em face de resolução de antinomias e 6) no caso do confronto entre regra e princípio (com as ressalvas hermenêuticas no que tange ao pamprincipiologismo).

Rev. Revista de Direitos Fundamentais nas Relações do Trabalho, Sociais e Empresariais| e-ISSN: 2525-

9903| Evento Virtual| v. 6 | n. 1 | p. 80-102 | Jan/Jun. 2020 

da justiça gratuita (art. 790-B da CLT). (SOARES, 2017)

A Frente Associativa da Magistratura e do Ministério Público (FRENTAS) é composta pela Associação Nacional dos Membros do Ministério Público (CONAMP), Associação Nacional dos Magistrados da Justiça do Trabalho (Anamatra), Associação Nacional dos Procuradores do Trabalho (ANPT), Associação dos Juízes Federais do Brasil (AJUFE), Associação Nacional dos Procuradores da República (ANPR), Associação dos Magistrados Brasileiros (AMB), Associação Nacional do Ministério Público Militar (ANMPM), Associação dos Membros do Ministério Público do Distrito Federal e Territórios (AMPDFT) e Associação dos Magistrados do Distrito Federal e Territórios (AMAGIS-DF). Tais entidades já se posicionaram publicamente contrárias à Lei 13.467, rechaçando a limitação pecuniária das indenizações por danos morais, baseadas nos salários das vítimas, o que viola o fundamento republicano da dignidade da pessoa humana (art. $1^{\circ}$, III) e por propiciar tratamento distinto a situações idênticas, afronta a garantia fundamental da isonomia, prevista no caput do art. $5^{\circ}$ da Constituição.

De forma mais preponderante, a ANAMATRA divulgou 125 enunciados aprovados sobre a interpretação da Reforma Trabalhista, dos quais, alguns de maior destaque preconizam (FELICIANO, 2017):

\footnotetext{
Tarifação do dano moral - A Plenária também acolheu tese no sentido de ser dever do Estado a tutela de reparação ampla e integral quando restar violada a moral das pessoas humanas, sendo inconstitucional a tarifação do dano extrapatrimonial pelo salário do trabalhador. Ao revés, devem ser aplicadas todas as normas existentes no ordenamento jurídico que possam imprimir, ao caso concreto, a máxima efetividade constitucional ao princípio da dignidade da pessoa humana. (ANAMATRA, 2017) Honorários de sucumbência e de peritos - As dificuldades que a nova lei impõe ao acesso à justiça gratuita também foram objeto de debates na Jornada. Nesse sentido, foi aprovado enunciado que prevê que as novas regras para os honorários sucumbenciais não se aplicam aos processos que já estejam tramitando quando da vigência da lei, em razão do princípio da causalidade, uma vez que a expectativa de custos e riscos é aferida no momento de propositura da ação trabalhista. Entendeuse, ainda, que o trabalhador beneficiário da justiça gratuita não pode ser condenado ao pagamento de honorários sucumbenciais em processos quaisquer. Também foi consenso a gratuidade no pagamento dos honorários de peritos do trabalho para os beneficiários da assistência judiciária gratuita, ante a violação, no particular, do art. $5^{\circ}$, XXXV e LXXIV, CF. (FELICIANO, 2017)
} 
Hermenêutica trabalhista configura o princípio da proteção que deve ser compreendido como fundamento para a aplicação de uma regra jurídica, sob pena de não ser reconhecida como norma jurídica trabalhista. (FELICIANO, 2017). Também, dentre as inúmeras associações de juízes, uma delas, denominada de Associação de Juízes para a Democracia, da qual também participam advogados, em seminário para debater a Reforma Trabalhista e extrair teses a serem adotadas por seus membros, apurou o seguinte resultado: "EMENTA: A lei $13.467 / 17$ é ilegítima, no sentido formal e material, devendo ser integralmente rejeitada." (TESES, 2018)

O que se constata, portanto, é uma grande rejeição de parcela dos Juízes do Trabalho, de associações e de jornadas construindo argumentos, a fim de buscar se eximir de aplicar diversos pontos da denominada Reforma Trabalhista sob o fundamento de haver aqui defeitos de origem, de forma, de inconstitucionalidades, além de vícios provocados pela não observância de Tratados e de Convenções internacionais os quais o Brasil se obrigou a observar.

Por outro lado, também existem, ainda que em quantidade bem menor, movimentos e jornadas no sentido de que a Reforma Trabalhista deve ser cumprida, que o Juiz deve cumprir a Lei 13.467. Nesse sentido, ocorre um projeto de articulação política, chamado Jornadas Brasileiras de Relações do trabalho, em nível nacional, com o único objetivo de conscientizar (convencer) o povo de que não há aberturas para a não aplicabilidade do que prevê a Reforma Trabalhista. (IBEC, 2018) ${ }^{18}$. A realidade é que os juízes não são livres para decidir de forma discricionária, sem qualquer amarra de cunho interpretativo, como propugnam Dworkin e Streck. Inclusive não podem decidir segundo a lei, sem observar se se encontram compatíveis com o ordenamento jurídico como um todo, em especial, evidentemente, se existe compatibilidade com a Constituição Federal, que é a norma ápice de nosso sistema jurídico ${ }^{19}$.

Os juízes devem decidir segundo a prova nos autos e fundamentar a sua decisão à luz do ordenamento jurídico (no sentido proposto por Dworkin) - ou seja, sem qualquer livre convencimento. Destarte, as jornadas e a associação, quando produzem enunciados, devem seguir padrões interpretativos, ressaltando-se que a mera menção do Princípio não é suficiente

\footnotetext{
${ }^{18}$ Este evento ocorreu no dia treze de julho (reunião-almoço), em um hotel de Porto Alegre/RS, patrocinado pela Presidência da República. Estive presente e fiquei em choque com as atrocidades que foram faladas.

${ }^{19}$ Nesse sentido Lenio Streck trabalha com a resposta constitucionalmente adequada.
} 
para afastar a regra, sob pena de haver a inserção de valores pessoais na equação pseudojurídica. Acerca disso, Lênio Streck assim se manifesta:

[...] No Brasil, a concepção de princípios como abertura interpretativa passou a representar um modo de justificar o voluntarismo judicial a partir de um critério ‘jurídico’ que permitiria certa liberdade aplicativa. Ocorre que, no fundo, a mera atribuição do nome 'princípio' a algo apenas serviu para garantir aparência de juridicidade, constituindo verdadeiro álibi retórico. O grande problema é que a comunidade jurídica passou cada vez mais a lançar mão do nome 'princípio' para justificar decisões discricionárias. Isso provocou uma fragmentação na aplicação judiciária, o que me levou a cunhar a expressão panprincipiologismo para designar esse fenômeno, que se transformou em uma verdadeira fábrica de princípios. (STRECK, 2017b, p. 150)

Outrossim, tem se observado em alguns enunciados uma resistência à aplicação da lei, de forma solipsista e precedente - como por exemplo, o Enunciado $n^{\circ} 1$ da comissão 08 da Anamatra, que assim dispõe:

Processo do trabalho. Incidente de desconsideração da personalidade jurídica: aplicação limitada. - i - no processo do trabalho, o redirecionamento da execução para o sócio não exige o incidente de desconsideração da personalidade jurídica (ARTS.133 A 137 DO CPC). II - [...]. (ANAMATRA, 2018)

O Enunciado em questão resta totalmente contrário ao artigo 855-A da CLT, o qual esclarece que "ao processo do trabalho se aplicará o incidente de desconsideração da personalidade jurídica previsto nos artigos. 133 a 137 da lei 13.105, de 16 de março de2015 Código de Processo Civil". Ao ler a íntegra da justificativa de tal enunciado, não se percebe qualquer inconstitucionalidade; pelo contrário, o Enunciado atinge o direito constitucional previsto no artigo $5^{\circ}$ LIV de que "Ninguém será privado da liberdade ou de seus bens sem o devido processo legal". A verdade é que o artigo 855-A da CLT corrige um equívoco histórico da Justiça do Trabalho, que usualmente penhorava bens de sócios, terceiros até mesmo dos companheiros dos devedores para depois discutir a legitimidade da penhora.

Por fim, os Enunciados, quando fundamentados por uma matriz interpretativa, coerente e íntegra que identifique a inconstitucionalidade ou confronte regras e princípios, podem ser bem recebidos, assumindo papel de doutrina. Caso contrário, podem representar atrocidades ao ordenamento jurídico trabalhista e deslegitimar o conteúdo de outros enunciados que integram a mesma jornada. 


\section{CONSIDERAÇÕES FINAIS}

Ao analisar as obras de Dworkin, inferiu-se que desenvolvem, preliminarmente, condições de produção de um discurso crítico na medida em que sua fala é interdisciplinar: Direito, moral, política e arte estão comprometidos na significação de um de tempo, de uma forma de vida que é a modernidade.

A realidade é que as críticas listadas por Dworkin ao positivismo de Hart agregaram mais subsídios à teoria da Decisão Jurídica. 2019. Logo, a estratégia de Dworkin se organiza em torno do fato de que, quando os juristas raciocinam ou debatem a respeito de direito e de obrigações jurídicas - particularmente naqueles casos difíceis nos quais conceitos parecem mais agudos - eles recorrem a padrões que não funcionam como regras, mas operam diferentemente como princípios, política e outros tipos de padrões.

A maior crítica de Dworkin é contra a discricionariedade, e para evitar decisões discricionárias, propõe uma teoria interpretativa com o intuito de evitar arbitrariedades dos juristas - fenômeno bastante nocivo ao Direito do Trabalho. Nesse contexto é que a exigência de coerência e de integridade (pressupostos Dworkianos que contornam a ideia de responsabilidade política) desvela-se de extrema relevância para que se compreenda o papel do Juiz na consolidação do projeto democrático e de sua responsabilidade para com a igualdade.

Dworkin propõe um jurista dotado de capacidades extraordinárias e sobre-humanas, chamado Hércules - que deve ser entendido como uma metáfora - destinado a desvendar em cada caso difícil os princípios que elucidem as regras vigentes e viabilizem a melhor justificação moral para a solução do caso, mantendo-se sempre no domínio da aplicação do direito, sem passar ao campo da criação de normas jurídicas.

Após o breve estudo acerca das contribuições de Ronald Dworkin quanto à matriz interpretativa, à coerência e à integridade e de Lenio Streck sobre a necessidade de uma resposta constitucionalmente adequada, passou-se a analisar a incoerência e a desintegridade da Reforma Trabalhista e, por isso, a atuação do Magistrado Hércules.

$\mathrm{Na}$ lógica deste trabalho, averiguou-se que o texto da Reforma Trabalhista pode ser considerado uma lei fundamentalmente injusta e, por isso, precisa de uma interpretação Rev. Revista de Direitos Fundamentais nas Relações do Trabalho, Sociais e Empresariais| e-ISSN: 2525-

9903| Evento Virtual| v. 6 | n. 1 | p. 80-102 | Jan/Jun. 2020 
íntegra e coerente para sua aplicação. Lenio Streck elenca seis hipóteses em que a lei - no caso, trabalhista, votada pelo Parlamento - pode deixar de ser aplicada, quando: a) for inconstitucional, b) se for possível uma interpretação conforme a Constituição, c) se for o caso de nulidade parcial sem redução de texto, d) no caso de uma inconstitucionalidade parcial com redução de texto, e) se se estiver em face de resolução de antinomias; e f) no caso do confronto entre regra e princípio (com as ressalvas hermenêuticas no que tange ao pamprincipiologismo).

Portanto, as decisões dos Juízes do Trabalho não se tratam de uma escolha livre a respeito de aplicar (ou não) as alterações da CLT, mas sim de uma interpretação, enfrentando os argumentos que compõem o caso, com argumentos de coerência e de integridade, com responsabilidade política, sem construir leis, pois “juiz não constrói leis; segue padrões interpretativos" (STRECK, 2015c) que devem estar de acordo com as normas constitucionais. Nessa seara, é certo que a Constituição Federal possui como viés direitos básicos e fundamentais atinentes à proteção do trabalhador das mais diferentes formas, na busca incessante pela igualdade e pela justiça. Pondera-se ainda que os Princípios de Liberdade e de Igualdade com frequência entram em conflito, pois às vezes o único meio eficaz de promover a igualdade exige certa limitação de liberdade, e as consequências de promover a liberdade são prejudiciais à igualdade.

Em suma, examinaram-se algumas críticas a respeito da massa de enunciados que surgiram - e vêm surgindo. Lenio Streck já publicou diversos escritos demonstrando sua crítica aos enunciados, defendendo que tentam transportar a realidade para dentro de conceitos e representam um desrespeito à autonomia do Direito - e até mesmo à forma como os poderes são organizados na CF. Ainda se depreendeu que alguns enunciados não restaram bem fundamentados - inclusive, com certa inconstitucionalidade. Finalmente, Enunciados fundamentados a partir de uma matriz interpretativa, coerente e íntegra, que identifique inconstitucionalidade ou em confronto entre regras e princípios, podem ser bem recebidos, assumindo papel de doutrina. Caso contrário, podem representar atrocidades ao ordenamento jurídico trabalhista e ainda podem deslegitimar o conteúdo de outros enunciados que fazem parte da mesma jornada. 


\section{REFERENCIAS}

\section{ASSOCIAÇÃO NACIONAL DOS MAGISTRADOS DA JUSTIÇA DO TRABALHO} (Anamatra). JORNADA DE DIREITO MATERIAL E PROCESSUAL DO TRABALHO, 2. Listagem dos enunciados aprovados, 2017, Brasília. Disponível em: $<$ http://www.jornadanacional.com.br/listagem-enunciados-aprovadosvis2.asp?ComissaoSel=8>. Acesso em: 25 maio 2018.

BRASIL. Câmara dos Deputados. Projeto de lei da Câmara n ${ }^{\circ}$ 38, de 2017 - Reforma Trabalhista. Disponível em: <https://www25.senado.leg.br/web/atividade/materias/-/materia/ 129049>. Acesso em: 06 ago. 2018.

BRASIL. Constituição (1988). Constituição da República Federativa do Brasil de 1988. Disponível em: <http://www.planalto.gov.br/ccivil_03/constituicao/constituicao.htm>. Acesso em: 05 ago. 2019.

BRASIL. Decreto-lei n. ${ }^{0}$ 5.452, de $1^{\circ}$ de maio de 1943. Aprova a Consolidação das Leis do Trabalho. Disponível em: <http://www.planalto.gov.br/ ccivil_03/ Decreto-Lei/Del5452.htm>. Acesso em: 06 ago. 2018.

BRASIL. Lei $\mathbf{n}^{\mathbf{0}}$ 13.105, de 16 de março de 2015. Código de Processo Civil. Disponível em: <http://www.planalto.gov.br/ccivIl_03/_Ato2015-2018/2015/Lei/L13105. htm>. Acesso em: 06 ago. 2019.

CHUEIRI, Vera Karam de. A dimensão jurídico-ética da razão: o liberalismo jurídico de Dworkin. In: ROCHA, Leonel Severo (Org.). Paradoxos da auto-observação: percursos da teoria jurídica contemporânea. 2. ed. rev. e atual. Ijuí: Unijuí, 2013.

CONSUlta PÚBLICA. PLC 38/2017 Projeto de lei da Câmara no 38 de 2017. Altera a Consolidação das Leis do Trabalho (CLT), aprovada pelo Decreto-Lei $\mathrm{n}^{\circ} 5.452$, de $1^{\circ}$ de maio de 1943, e as Leis $n^{\circ}$ s 6.019, de 3 de janeiro de 1974, 8.036, de 11 de maio de 1990, e 8.212, de 24 de julho de 1991, a fim de adequar a legislação às novas relações de trabalho.

Disponível em: <https://www12.senado.leg.br/ecidadania/ visualizacaomateria?id=129049>. Acesso em: 06 ago. 2019.

DWORKIN, Ronald. Levando os direitos a sério. Tradução de Nelson Boeira. 2. ed. São Paulo: Martins Fontes, 2007.

DWORKIN, Ronald. O império do direito. São Paulo: Martins Fontes, 1999.

DWORKIN, Ronald. Uma questão de princípio. Tradução de Luís Carlos Borges. 2. ed. São Paulo: Martins Fontes, 2005.

FELICIANO, Guilherme Guimarães et al. Anamatra e associações de procuradores, auditores e advogados criticam portaria do MTE sobre trabalho escravo. Porto Alegre, 18 out. 2017. Disponível em: <https://www.anamatra.org.br/imprensa/noticias/25794-

Rev. Revista de Direitos Fundamentais nas Relações do Trabalho, Sociais e Empresariais| e-ISSN: 2525- 
trabalho-escravo-anamatra-e-associacoes-de-procuradores-auditores-e-advogados-criticamportaria-do-ministerio-do-trabalho>. Acesso em: 25 maio 2019.

FERRAREZE FILHO, Paulo; MATZENBACHER, Alexandre (Orgs.). Proteção do trabalhador: perspectivas pós-constitucionais. Rio de Janeiro: Lumen Juris, 2016.

HONÓRIO, Cláudia; OLIVEIRA, Fabrício Gonçalves de. Retrocesso sem precedentes: a reforma trabalhista e os danos extrapatrimoniais. Carta Capital, [S.1.], 14 ago. 2017. Disponível em: < http://justificando.cartacapital.com.br/2017/08/14/retrocesso-semprecedentes-reforma-trabalhista-e-os-danos-extrapatrimoniais/>. Acesso em: 14 set. 2017.

INSTITUTO BRASILEIRO DE ENSINO E CULTURA (IBEC). Jornadas Brasileiras de Relações do trabalho, 2018, Porto Alegre. Disponível em: <WWW.ibecnet.com.br/>. Acesso em: 25 maio 2019.

LEDUR, José Felipe. A proteção como função jurídico-objetiva dos direitos fundamentais nas relações de trabalho. Cadernos da Escola Judicial do TRT da $4^{\text {a }}$ Região, Porto Alegre, n. 5, 2010.

MOTTA, Francisco José Borges. Ronald Dworkin e a construção de uma teoria hermenêutica adequada da decisão jurídica democrática. 2014. 292 f. Tese (Doutorado em Direito) -- Programa de Pós-Graduação em Direito, Universidade do Vale do Rio dos Sinos (Unisinos), São Leopoldo, 2018. Disponível em: <http://biblioteca.asav.org.br/vinculos/ 000014/ 0000142C.pdf>. Acesso em: 15 jul. 2019.

PAES, Arnaldo Boson. O STF e a reforma trabalhista. 5 mar. 2018 Disponível em: <https:// www.anamatra. org.br/artigos/26246-o-stf-e-a-reforma-trabalhista>. Acesso em: 06 ago. 2019.

PIRES, Horácio de Senna. Direito do trabalho: a atualidade do princípio da proteção. Rev. TST, Brasília, DF, v. 77, n. 2, p. 1, abr./jun. 2011.

ROCHA, Leonel Severo. Introdução. In: ROCHA, Leonel Severo. Paradoxos da autoobservação: percursos da teoria jurídica contemporânea. 2. ed. rev. e atual. Ijuí: Unijuí, 2013.

RODRIGUEZ, César. La decisión judicial: el debate Hart-Dworkin. Santafé de Bogotá: Siglo del Hombre: Facultad de Derecho Universidad de los Andes, 1997.

SOARES, Saulo. A inconstitucionalidade e o retrocesso social da reforma trabalhista. 04 jun. 2017. Disponível em: <https://www.saudeocupacional.org/2017/08/ainconstitucionalidade-e-o-retrocesso-da-reforma-trabalhista.html>. Acesso em: 14 set. 2017.

STRECK, Lenio Luis. A febre dos enunciados e a constitucionalidade do ofurô! Onde está o furo? Consultor Jurídico, São Paulo, 10 set. 2015f. Disponível em: 
$<$ https://www.conjur.com. br/2015-set-10/senso-incomum-febre-enunciados-ncpcinconstitucionalidade-ofuro >. Acesso em: 04 ago. 2019.

STRECK, Lenio Luis. Na Dacha, teóricos do mundo dizem: a verdade não está no enunciado! Consultor Jurídico, São Paulo, 19 de outubro de 2017a. Disponível em: $<$ https://www.conjur. com.br/2017-out-19/senso-incomum-dacha-teoricos-mundo-dizemverdade-nao-enunciado>. Acesso em: 07 ago. 2019.

STRECK, Lênio Luiz. As provas e o novo CPC: a extinção do poder de livre convencimento. In: FELIX JOBIM, Marco; SANTOS FERREIRA, William (Orgs.). Direito probatório. 2. ed. Salvador: Juspodivm, 2015d.

STRECK, Lenio Luiz. Coerência e integridade de Ronald Dworkin: uma análise de sua aplicação ao contexto brasileiro. In. OMMATI, José Emílio Medauar. Ronald Dworkin e o direito brasileiro. Rio de Janeiro: Lume Juris, 2016.

STRECK, Lenio Luiz. Constituição é contra impeachment de Dilma por fato do mandato anterior. Consultor Jurídico, São Paulo, 24 ago. 2015 a. Disponível em:

$<$ https://www.conjur. com.br/2015-ago-24/lenio-streck-constituicao-impeachment-mandatoanterior>. Acesso em: 06 ago. 2019.

STRECK, Lenio Luiz. Dicionário de hermenêutica: quarenta temas fundamentais da teoria do direito à luz da crítica hermenêutica do direito. Belo Horizonte: Letramentos, 2017b.

STRECK, Lenio Luiz. Dilema de dois juízes diante do fim do livre convencimento no NCPC. In: DIDIER Jr, Fredie (Coord.); MACÊDO, Lucas Buril; PEIXOTO, Ravi; FREIRE, Alexandre (Orgs.). Doutrina selecionada: processo de conhecimento - provas. Salvador: Juspodivm, 2015 e. v. 3. (Coleção Novo CPC).

STRECK, Lenio Luiz. Não há elementos jurídicos para impeachment de Dilma, rebatem juristas. Consultor Jurídico, São Paulo, 4 fev. 2015b. Disponível em: <https://www.conjur. com.br/2015-fev-04/nao-elemento-juridico-impeachment-dilma-dizem-advogados >. Acesso em: 06 ago. 2019.

STRECK, Lenio Luiz. O que é decidir por princípios? a diferença entre a vida e a morte. Consultor Jurídico, São Paulo, 6 ago. 2015c. Disponível em: <https://www.conjur.com.br/ 2015-ago-06/senso-incomum-decidir-principios-diferenca-entre-vida-morte>. Acesso em: 03 ago. 2017.

STRECK, Lenio Luiz. O que é isto - decido conforme minha consciência? Porto Alegre: Livraria do Advogado, 2010.

STRECK, Lenio Luiz. Por que tanto se descumpre a lei e ninguém faz nada? Consultor Jurídico, São Paulo, 14 nov. 2013. Disponível em: <https://www.conjur.com.br/2013-nov14/senso-incomum-tanto-descumpre-lei-ninguem-faz-nada>. Acesso em: 07 ago. 2019. 


\section{A DESINTEGRIDADE E A INCOERÊNCIA DA REFORMA TRABALHISTA:}

A NECESSIDADE DE UMA RESPOSTA ADEQUADA

TESES. Jornada Trabalhista da Associação Juízes para Democracia, 1. ADJ, São Paulo, 26 jul. 2018. Disponível em <http://ajd.org.br/teses-da-i-jornada-trabalhista-da-associacao-juizes-parademocracia/>. Acesso em: 25 maio 2019. 